pts on TNFi. On average, pts on ABA were older and had more prior bDMARDs Adjusting for potential confounding factors did not modify the results qualitatively (figure 1), with significantly longer time before discontinuation in seropositive vs seronegative pts on ABA (adj. HR: 0.74 (95\% Cl: 0.67-0.84) but not on TNFi (adj. HR: 0.99 (95\% Cl: 0.94-1.04)).

The proportion of pts reaching DAS28 remission or LDA at 1 year was significantly higher for seropositive vs seronegative pts on ABA (difference in proportion: remission: $5.0 \%$; LDA: $9.7 \%$ ), but similar for seropositive vs seronegative pts on TNFi (difference in proportion: remission: $-2.7 \%$; LDA: $-2.3 \%$ ).

Conclusions: Data from this large pooled registry suggests that seropositivity in $R A$ pts is associated with increased drug retention and effectiveness for $A B A$ but not for TNFi.

REFERENCE:

[1] Kristensen, et al. A\&R 2006;(54):600-6.

Acknowledgements: Unrestricted research grant from BMS

Disclosure of Interest: D. Courvoisier Consultant for: BMS, D. Mongin: None declared, M. Hetland Consultant for: Abbvie, Biogen, BMS, CellTrion, MSD, Novartis, Orion, Pfizer, Samsung, UCB, K. Pavelka Grant/research support from: Ministry of Health, Czech Republic 023728, Consultant for: AbbVie, Roche, MSD, BMS, Amgen, Egis, Medac, UCB, Pfizer, Biogen, C. Turesson Grant/research support from: Abbvie, Bristol Myers-Squibb, Roche. Consultant for: MSD, Bristol Myers-Squibb, Roche, Paid instructor for: Abbvie, Bristol-Myers Squibb, Janssen, MSD, Pfizer, Roche, UCB, S. A. Bergstra: None declared, T. Kvien Grant/ research support from: AbbVie, BMS, MSD, Pfizer, Roche, UCB, Consultant for: AbbVie, Biogen, BMS, Boehringer Ingelheim, Celgene, Celltrion, Eli Lilly, Epirus, Hospira, Merck-Serono, MSD, Mundipharma, Novartis, Oktal, Orion Pharma, Hospira/Pfizer, Roche, Sandoz, UCB, M. J. Santos: None declared, V. Hernandez: None declared, F. lannone Consultant for: BMS, J.-E. Gottenberg Consultant for: BMS, X. Mariette Consultant for: BMS, S. Kubo Speakers bureau: BMS, Pfizer, Takeda, Y. Tanaka Grant/research support from: Mitsubishi-Tanabe, Takeda, Bristol-Myers, Chugai, Astellas, Abbvie, Daiichi-Sankyo, Pfizer, Eisai, Ono, Consultant for: Daiichi-Sankyo, Astellas, Pfizer, Mitsubishi-Tanabe, BMS, Chugai, YL Biologics, Eli Lilly, Sanofi, Janssen, UCB, D. Choquette: None declared, R. lonescu: None declared, A. Finckh Grant/research support from: BMS, Consultant for: BMS, AbbVie, AB2BIO, MSD, Pfizer, Roche, UCB DOI: 10.1136/annrheumdis-2018-eular.3312

\section{FRI0111 ANALYSIS OF REAL-LIFE INFLIXIMAB AND ADALIMUMAB DATA: DRUG SWITCHING AND FATE OF ANTIDRUG ANTIBODIES AND TROUGH LEVELS OVER TIME}

$\underline{D . ~ H o}^{1}$, S. Valtanen ${ }^{2}$, M. Havana ${ }^{2}$, L. Kröger ${ }^{3}$, K. Eklund $^{4}$, T.S. Jokiranta ${ }^{1,2}$ ${ }_{1}^{1}$ Research Programs Unit, Immunobiology, University of Helsinki; ${ }^{2}$ United Medix Laboratories, Helsinki; ${ }^{3}$ Kuopio University Hospital, Pediatric Rheumatology, Kuopio; ${ }^{4}$ Helsinki University and Helsinki University Hospital, Rheumatology, Helsinki, Finland

Background: Infliximab (IFX) and adalimumab (ADL) are biological drugs used in the treatment of rheumatoid arthritis (RA), spondyloarthropathy ( $S p A)$, and juvenile idiopathic arthritis (JIA). Development of antidrug antibodies (ADAb) may lead to increased drug clearance and loss of therapeutic drug trough levels (TL). Switching to another drug may be necessary after ADAb development.

Objectives: To use real-life data from a large Finnish rheumatology patient cohort to determine the association between drug switching and ADAbs and the fate of ADAbs and TLs after ADAb development.

Methods: Serum samples for IFX or ADL ADAb and TL measurements from 1345 (567 RA, 479 SpA, and 299 JIA) rheumatology patients were taken on a clinical basis in daily practice in 20 Finnish referral hospitals. ADAb analyses were performed at Sanquin laboratories (Amsterdam, The Netherlands) using radioimmunoassays; TL analyses were performed at United Medix Laboratories (Helsinki, Finland) using commercial methods (Promonitor ELISA, Progenika Biopharma). Samples were collected and analysed from January 2012 until September 2017. ADAb values $\geq 12 \mathrm{AU} / \mathrm{ml}$ were considered positive; $A D A b$ values were classified as low (12-30 AU/ml), intermediate (30-100 AU/ml) and high $(\geq 100 \mathrm{AU} / \mathrm{ml})$

Results: On the basis of TL data, we identified 67 patients (5\%) who switched drugs. Of these patients, $47(70.2 \%)$ provided ADAb measurements for the first drug; 33 (49.3\%) patients were ADAb positive. Most (22 patients, $63.6 \%$ ) had high ADAbs. Forty-nine (73.1\%) patients provided ADAb measurements for the second drug. Of these patients, 11 (16.4\%) were ADAb positive against the second drug; seven (63.6\%) had high ADAbs. We identified 48 (3.6\%) ADAb-positive patients who provided at least one follow-up ADAb measurement. Of these patients, $32(66.7 \%)$ experienced ADAb loss; most (24 patients, $50 \%$ ) experienced complete ADAb loss (most recent ADAb value $\leq 12 \mathrm{AU} / \mathrm{ml}$ ). Twenty-five patients that experienced ADAb loss had available TL measurements both before and after ADAb loss; 23 (92\%) had increased TL after ADAb loss. Of the 16 patients that experienced ADAb gain, only $3 / 11$ (27.3\%) patients that had available TL measurements both before and after ADAb gain had increased TL after ADAb gain.

Conclusions: ADAb positivity is associated with drug switching; ADAb development against a second biologic drug is common. A significant proportion of ADAb positive patients lose ADAbs over time. ADAb loss is associated with TL increase. Disclosure of Interest: D. Ho Consultant for: Pfizer Oy, S. Valtanen: None declared, M. Havana: None declared, L. Kröger Consultant for: Roche, K. Eklund Grant/research support from: Pfizer, Speakers bureau: Abbvie, MSD, Pfizer, BMS, T. S. Jokiranta Grant/research support from: Pfizer, Consultant for: Abbvie MSD, Pfizer, UCB

DOI: 10.1136/annrheumdis-2018-eular.3052

\section{FRI0112 PERSISTENCE ON TUMOUR NECROSIS FACTOR INHIBITOR (TNFI) MONOTHERAPY AFTER ACHIEVING REMISSION OR LOW DISEASE ACTIVITY (LDA) ON COMBINATION THERAPY AMONG PATIENTS WITH RHEUMATOID ARTHRITIS (RA)}

D.A. Pappas $^{1,2}$, H.J. Litman ${ }^{2}$, T. Lesperance ${ }^{3}$, S. Rebello², E. Karis ${ }^{4}$, G. Kricorian ${ }^{4}$, W. Hua ${ }^{2}$, N. Accortt ${ }^{4} .{ }^{1}$ Columbia University College of Physicians and Surgeons, New York, NY; ${ }^{2}$ Corrona, LLC, Waltham, MA; ${ }^{3}$ DOCS Global, Inc., North Wales, $P A ;{ }^{4}$ Amgen Inc., Thousand Oaks, CA, USA

Background: Combination therapy with TNFis and conventional synthetic disease-modifying antirheumatic drugs (csDMARDs) is standard for moderate to severe RA.

Objectives: To estimate persistence with etanercept (ETN) or other TNFi monotherapy among RA patients who achieved remission/LDA on combination TNFi + CSDMARD therapy and then discontinued the csDMARD.

Methods: Data from RA patients in the Corrona registry during 10/1/2001-8/31/ 2017 were analysed. All patients had to be treated with TNFi +csDMARD combiination therapy and to have reached Clinical Disease Activity Index remission/ LDA and then discontinue the csDMARD (index date). ETN (fusion protein comprising TNF receptor and human IgG1 Fc) and other TNFi therapies (monoclonal antibodies: adalimumab, certolizumab pegol, golimumab, and infliximab) were analysed separately. Outcomes were percentages of patients persistent on index TNFi monotherapy, discontinued index TNFi, switched (to another biologic or to csDMARD monotherapy), or added csDMARD therapy (to receive combination therapy) at 6 months (primary analysis) and 12 months post-index.

Results: Data from 617 patients were analysed (182 ETN, 435 other TNFi); mean age (standard deviation [SD]) was 57.4 (13.3) years, $73 \%$ were female. Mean time (SD) in remission/LDA before csDMARD discontinuation was 17.0 (24.3) months. Rates of monotherapy persistence at 6 months were $56 \%$ for ETN and $45 \%$ for other TNFi (table 1). Patients with $\geq 6$ month persistence on monotherapy had mean duration (SD) of 28.2 (22.1) months on ETN monotherapy or 27.8 (23.3) months on other TNFi monotherapy. Rates of persistence for all patients at 12 months were $46 \%$ for ETN and $33 \%$ for other TNFi. Patients with $>12$ month persistence had mean duration (SD) of 35.9 (22.6) months on ETN monotherapy or 39.3 (24.4) months on other TNFi monotherapy. For a subset of patients with $<6$ months in remission/LDA before index date ( $44 \%$ of patients), rates of monotherapy persistence at 6 months were $60 \%$ for ETN and $42 \%$ for other TNFi.

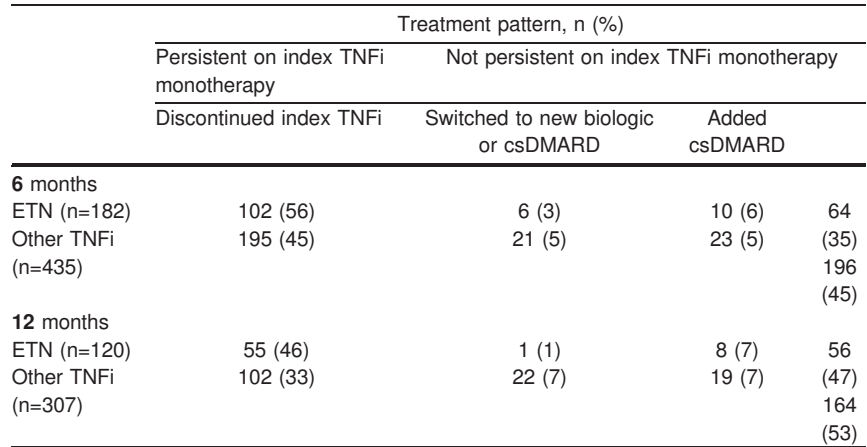

Conclusions: Monotherapy with ETN or other TNFi is an option for patients in remission/LDA; $>50 \%$ of patients on ETN remained on monotherapy 6 months after discontinuing their csDMARD.

Acknowledgements: This study was sponsored by Corrona, LLC and the analysis was funded by Amgen Inc.

Disclosure of Interest: D. Pappas Employee of: Corrona, LLC, H. Litman Employee of: Corrona, LLC, T. Lesperance Consultant for: Amgen Inc., S. Rebello Employee of: Corrona, LLC, E. Karis Shareholder of: Amgen Inc., Employee of: 